\title{
Model of Human Occupation as a framework for implementation of Motivational Interviewing in occupational rehabilitation
}

\author{
Joanne Park ${ }^{\mathrm{a}, \mathrm{b}, *}$, Douglas P. Gross ${ }^{\mathrm{c}}$, Fahreen Rayani ${ }^{\mathrm{b}}$, Colleen M. Norris ${ }^{\mathrm{d}}$, Mary Roduta Roberts ${ }^{\mathrm{a}}$, \\ Carole James $^{\mathrm{e}}$, Christine Guptill ${ }^{\mathrm{a}}$ and Shaniff Esmail ${ }^{\mathrm{a}}$ \\ ${ }^{a}$ Department of Occupational Therapy, University of Alberta, Edmonton, Canada \\ ' Workers' Compensation Board of Alberta Millard Health, Edmonton, Canada \\ ${ }^{c}$ Department of Physical Therapy, University of Alberta, Edmonton, Canada \\ ${ }^{\mathrm{d}}$ Faculty of Nursing and Faculty of Medicine, University of Alberta, Edmonton, Canada \\ ${ }^{\mathrm{e} S c h o o l}$ of Health Sciences, University of Newcastle, Newcastle, Australia
}

Received 8 November 2017

Accepted 20 August 2018

\begin{abstract}
.
BACKGROUND: A conceptual framework is needed to understand injured workers' decision-making and inform evidencebased interventions to address behavior change regarding return-to-work (RTW). The Model of Human Occupation (MOHO) can help with understanding how an injured worker's characteristics can generate behavior change while Motivational Interviewing (MI) can help facilitate behavior change.

OBJECTIVE: This theoretical paper provides an overview of how MOHO and MI can be applied and integrated in occupational rehabilitation. The objectives of this paper are to: (1) evaluate MOHO as a framework for supporting occupational therapists (OTs) in occupational rehabilitation; (2) describe MI as a suitable approach for OTs in occupational rehabilitation; and (3) compare and integrate MOHO and MI.

METHOD: Several important works and reviews were used to integrate MOHO and MI with occupational rehabilitation. IMPLICATIONS FOR PRACTICE: The identification of a model and approach to support OT practice in occupational rehabilitation can assist OTs to determine the most appropriate interventions and contribute to standards of best practice. CONCLUSIONS: Integrating MOHO and MI provides a comprehensive framework for understanding impairment and RTW change processes with the potential to reduce work disability and improve RTW outcomes.
\end{abstract}

Keywords: Return-to-work, readiness for change, work disability

\section{Introduction}

Occupational rehabilitation is a growing field of research and practice that has contributed to significant developments towards understanding the

\footnotetext{
*Address for correspondence: Joanne Park, 3-48 Corbett Hall, University Of Alberta Edmonton, Alberta, Canada T6G $2 \mathrm{G} 4$. Tel.: +1 (780) 492 2499; Fax: +1 (780) 492 1626; E-mail: jypark@ualberta.ca.
}

return-to-work (RTW) process and facilitating RTW outcomes. However, studies of RTW practices indicate variable [1] or minor changes to overall work disability rates $[2,3]$. This has been, at least in part, attributed to a lack of a comprehensive theoretical framework addressing work disability and RTW. This is further complicated by a substantial gap between theories and models used by researchers and frontline occupational rehabilitation practitioners $[2,4,5]$. 
In addition, there are limited intervention approaches currently used in occupational rehabilitation to ensure effective and meaningful behavior change that considers the readiness of the injured worker to RTW $[2,4,6]$. There is a need for an integrated conceptual framework to understand injured workers' decision-making processes and inform evidencebased interventions that address behavior change regarding RTW [2, 4].

Occupational rehabilitation is an important practice area in occupational therapy (OT) and those in the area are expected to practice in a manner that is theory-informed, evidence-based, and occupation-focused [7]. However, this standard of best practice presents a significant challenge because current practice is not strongly grounded in theory, occupation, or evidence [7]. Furthermore, occupational therapists (OTs) are challenged with linking evidence-based tools with specific conceptual models that support client-centered beliefs and practice. Successful client-centered practice depends on the clients' desire and ability to participate in decisionmaking processes and the inclusion of the client in the decision-making process [8]. Evidence suggests there may be a perceptual gap between these two components resulting in recommendations for OTs to implement a systematic approach involving clients in decision-making processes [8].

The Model of Human Occupation (MOHO, See Fig. 1) is an occupation-based model used to guide OT practice [9]. MOHO provides a broad and integrative view of occupation and attempts to explain how human occupation is motivated, patterned, and performed [10]. Evidence indicates MOHO is the most extensively used occupation-based model among

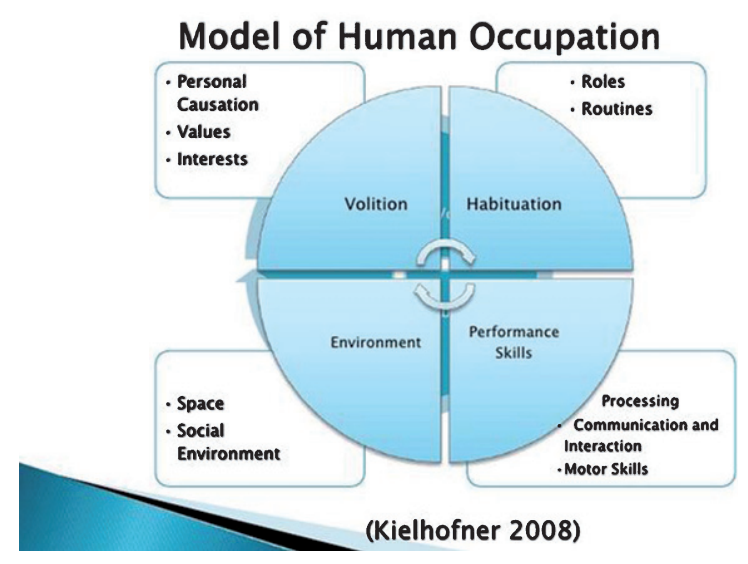

Fig. 1. Model of Human Occupation.
OTs worldwide [7] and MOHO has previously been applied to occupational rehabilitation to guide interventions and programs $[7,11]$.

Motivational Interviewing (MI) is a directive, client-centered, evidenced-based approach that elicits behavioral change by assisting clients to resolve ambivalence [12]. A key philosophy of MI is clientcentered practice which emphasizes the importance of autonomy, recognizing the clients' right and capacity for self-direction and collaboration, a partnership that honours the client's expertise and perspectives. The clinical procedure of MI involves a conversation about change with the primary purpose of strengthening the client's motivation for change based on the client's values and interests [12-14]. MI has been used to address maladaptive behavior and promote healthy adaptive behaviors [15] and has recently been applied to occupational rehabilitation to improve RTW outcomes [16, 17].

This paper provides an overview of how MOHO and MI can be applied and integrated in occupational rehabilitation. The objectives of this paper are to: (1) evaluate MOHO as a framework for supporting OTs in occupational rehabilitation; (2) describe MI as a suitable approach for OTs in occupational rehabilitation; and (3) compare and integrate $\mathrm{MOHO}$ and MI.

\section{Method}

This theoretical paper provides an overview of how MOHO and MI can be applied and integrated in occupational rehabilitation. Several important works and reviews were used to integrate MOHO and MI with occupational rehabilitation. However, the recent literature related to $\mathrm{MOHO}$ in this area is scarce and more research on the use of MOHO-based approaches is recommended.

\section{Model of Human Occupation and occupational rehabilitation}

The following aspects of MOHO support its application to occupational rehabilitation: (1) MOHO is an occupation-based theoretical model that can guide occupational rehabilitation practice; (2) MOHO has previously been used to guide occupational rehabilitation intervention and programs; (3) MOHO considers the importance of environment and how context can influence work behavior and participa- 
tion in occupation; (4) MOHO provides a broad and integrated approach for working with the complex needs of injured workers; and (5) MOHO is a clientcentered theoretical model that can help bridge the gap between client-centered philosophy and practice in occupational rehabilitation.

MOHO describes how work behavior and occupations are the result of interactions between concepts related to person characteristics (volition, habituation, and performance capacity) and the environment [7]. The identification of a model that can support OT practice in occupational rehabilitation can enhance professional identity and competence and assist OTs to meet standards of best practice. In comparison to other OT models, the MOHO was chosen for review and integration with MI in occupational rehabilitation because it provides a profound understanding of why (the meaning) occupation is performed.

\subsection{Volition}

Two seminal works, Kielhofner [9] and Kielhofner et al. [18], informed many of the ideas in this section. OT based on MOHO requires the identification and understanding of an individual's volition. Volition is described as the process through which individuals find meaning, which motivates them to select activities in which they want to participate. Volition is shaped by thoughts and feelings that reflect a person's values (beliefs about what is important to do, how to perform occupations, and what to commit to); interests (experience of pleasure and fulfilment in occupation); and personal causation (beliefs about one's capacities and effectiveness). MOHO stresses that volition is fundamental to OT practice, because the therapy process requires clients to make decisions about occupations, which influence therapy outcomes. Volition factors such as job satisfaction and personal causation are essential to the decisionmaking process in RTW and the ability to succeed at work [7]. Injured workers who see work as a strong social value necessary for independence and to improve life circumstances, may be more compelled to RTW. However, this value may be influenced by culture, and not everyone values work to the same degree or in the same way. Occupational interests significantly influence the type of work people choose. Individuals who enjoy and are interested in their work have a greater investment and attraction for work compared to individuals whose work circumstances provide little opportunity for enjoyment and satisfaction. Negative work circumstances can, therefore, negatively affect desire for work. Personal causation is also an important consideration for injured workers when selecting employment to return to or potential career opportunities. Injured workers' accurate understanding of their personal capacity and selfefficacy will assist them in using their skills and abilities effectively to select work at which they will succeed.

The Worker Role Interview (WRI) is a workrelated assessment based on MOHO concepts [7]. The WRI can be used in conjunction with work capacity evaluations to assess psychosocial and environmental factors related to work that can impact components of volition such as interests and personal causation $[7,19]$. The WRI can be used with injured workers who have physical or mental disabilities and can provide important insight into understanding injured workers' motivation for work [7].

\subsection{Habituation}

Habituation is a concept in $\mathrm{MOHO}$ that refers to the organization of actions into patterns and routines that are governed by habits and roles and shaped by context and the environment. Habits operate differently within various environmental contexts, which influence how individuals perform routine activities and behave within these contexts. Roles are the functions assumed by individuals, and the internalization of roles is a process that provides individuals with an identity. A sense of obligation that accompanies an identity subsequently influences behavior to fulfil the role requirements shaped by social systems. The recurrent patterns of work behavior that make up a significant portion of work are the result of an internalized worker role and habits. Barriers to RTW can arise from long-term disruption to an individual's work role and habits, while previous work history and ability to identify and re-adopt work role expectations support RTW success [7]. Competent work behavior results from successful integration by the worker of the norms, behavior, and rhythms inherent to the workplace. Furthermore, workers need to understand their worker role and, at times, must be able to transfer this understanding across different work environments. When applying MOHO, an essential task of therapy involves constructing or reconstructing habits and roles impacted by impairments or environmental circumstances to allow the individual to readily participate in routine occupations such as work.

The Dialogue About Ability Related to Work (DOA) is another MOHO work-related instrument 
that can be used to assess how volition and roles can impact work ability [7]. This assessment can be used with clients who have psychiatric and psychosocial issues, [7] which could affect workers' habits and roles and ultimately the motivation to RTW after a workplace injury has occurred.

\subsection{Performance capacity}

Performance capacity is influenced by an individual's underlying physical and mental abilities as well as how these abilities are used and experienced [9]. Performance capacity considered alongside habituation and volition provides a broader view of the worker's behavior. Personal causation, interests, values, roles, and habits can all be affected when an injured worker experiences changes to their performance capacity. Also, permanent disruptions in performance capacity often require changes to one or more elements of volition and habituation, for the worker to successfully adapt to the disruption. Changes to performance capacity, therefore, often require recruitment of volition and habituation. For example, if an injured worker believes one cannot functionally use the right arm or fears an increase in pain or re-injury when attempting movement then the worker may choose to limit movement of the arm [18]. This results in maintenance or exacerbation of performance capacity limitation [18]. In this circumstance, changes to volition and habituation are essential to attain changes in performance capacity. MOHO emphasizes the significance of acknowledging the experience of performance, specifically, the experience of being limited in performance. MOHO also asserts that attention should be placed on how individuals experience impairment.

The Assessment of Work Performance (AWP) is a work-related assessment based on the concepts of $\mathrm{MOHO}$ that assesses motor, process, communication and interaction skills [7]. This assessment can determine how efficiently an injured worker completes a work activity and can be used with any worker who experiences a work-related injury [7]. The AWP can provide essential information for OTs in determining how work-related injuries can impact personal characteristics influencing how injured worker's view what work tasks are important or how occupations are performed. In addition, the AWP can provide information about an injured worker's fulfilment in participating in occupational tasks, and their beliefs about how effective they are in their occupational roles.

\subsection{Environment}

From a MOHO perspective, the environment can significantly impact occupational behavior. Motivation, organization, and occupational performance are all influenced by the environment. The environment includes contextual characteristics such as physical, social, cultural, economic, and political features. Several dimensions of the environment can influence behavior and how individuals think and feel about their behavior. While a lack of environmental support and negative perceptions of the work environment can impede work success [7], it is rarely one single factor that accounts for success or failure of work. MOHO postulates that the environment and inner characteristics of a person are connected and together influence occupational behavior.

The Work Environment Impact Scale (WEIS) is a MOHO-based work assessment that evaluates features of the physical and social work environments that can either support or hinder the performance, satisfaction, and well-being of an injured worker [7]. The WEIS can identify characteristics of the work environment that support successful work experiences and workplace accommodations [7] and can be used together with other MOHO based work-assessments to evaluate how occupational behaviour is impacted by personal characteristics and the environment.

\section{5. МOHO summary}

MOHO is a theoretical model that assists in addressing broad issues that influence work ability in a variety of impairments and can be used with a wide range of individuals throughout the life course in various settings [9]. MOHO explains aspects of healthy and maladaptive occupations that can occur due to workplace injury. The concepts of MOHO can address motivation for participating in work; patterns of work behaviours; nature of skilled occupational performance; and the influence the work environment can have on occupations [20]. MOHO appears to be a useful model in occupational rehabilitation and could work in conjunction with existing RTW models. This integrated model could provide OTs with a framework to explain participation in occupational behavior.

\section{Motivational Interviewing and occupational rehabilitation}

Although the role of OTs in occupational rehabilitation settings can vary, a broad and integrated 
approach such as $\mathrm{MOHO}$ requires the acknowledgement of all aspects of RTW. Physical, psychological, and social factors may contribute to ambivalence in the RTW process [21]. For OTs working with injured workers who are ambivalent about RTW, this can be a challenge because an evidence-based, formalized approach has not yet been established. Evidence suggests work disability and the RTW process should be conceptualised into developmental stages regarding readiness for work activity. Transition between stages and overall readiness for work are influenced by physical, psychological and social factors that can create uncertainty about ability to function or RTW [22, 23]. There is an increasing emphasis in occupational rehabilitation on how psychosocial factors contribute to prolonged work disability; however, further research is needed on practical approaches and interventions that address psychosocial and behavioral barriers to RTW [16, 17, 22, 23]. In addition, OTs report several challenges when implementing evidence-based principles into practice [7].

MI has proven to be a versatile treatment in various practice areas, capable of supporting behavior change in a variety of health conditions and lifestyle problems [15, 24].

\subsection{MI and stages of change}

MI is typically discussed in the context of the stages of change used in the Readiness for Change Model [25]. The Readiness for Change Model has been applied to occupational rehabilitation with the stages of change originally described by Prochaska et al. [26] as a framework for describing the change process. The five stages of behavioral change were related to RTW by Franche et al. [25] and described as: (1) Precontemplation - Injured workers absent from work are not considering or initiating behavior associated with RTW; (2) Contemplation - Injured workers are ambivalent about RTW; (3) Preparation - Injured workers seek information about RTW, test their abilities to RTW, and make tangible RTW plans; (4) Action - Injured workers have put their RTW plan into action and are working in some capacity; and (5) Maintenance - Injured workers use skills and support systems to manage situations or behavior that can interfere with RTW. The stages of change provide a framework for understanding the process of behavioral change as a representation of an individual's level of readiness for change, while MI provides the means to facilitate the change process [27, 28]. An individual's readiness for change is influenced by inner characteristics as well as the environmental context as described in $\mathrm{MOHO}$, which explains the influence on participation in occupational behavior [9]. For example, individuals with a strong worker role identity are more likely to invest effort and time into work, but an injured worker in the Precontemplation stage may not identify strongly with the worker role and find little reason to RTW. Furthermore, for most working adults, competence is determined by one's capacity for and efficacy at work [18]. Injured workers in the Contemplation stage may be struggling with personal causation, comprised of personal capacity and sense of self-efficacy, which results in ambivalence regarding ability to RTW [18, 25]. Performance capacity influences work adaptation, and injured workers in the Preparation stage may start to test physical and mental abilities and to prepare for RTW. In the Action stage and Maintenance stage, integration of the person's inner characteristics and the environment are of critical importance as the injured worker has returned to work. Injured workers who feel valued, supported, and rewarded for their efforts have more incentive to continue working [18].

Although it is not necessary to allocate individuals to a specific stage of change when engaging in MI, it may be beneficial to understand the client's level of readiness to adjust the intervention approach and more fully meet the client at the current stage of change [13]. For example, an OT knowing an injured worker is in the Contemplation stage, may focus on exploring ambivalence in contrast to when MI is less useful and even counterproductive if an injured worker is in the Action phase [13]. The use of a tool informing what stage of change the injured worker is in could help OTs meet injured workers at their level of readiness in the change process. A tool based on the stages of change, such as the Readiness for Return-to-Work Scale, should be evaluated within occupational rehabilitation settings to determine its function and applicability during MI [25].

\subsection{Characteristics of MI}

MI has been examined across an extensive range of target behaviors and has been found to be effective in reducing maladaptive behaviors such as alcohol abuse, drug addiction, and smoking as well as promoting healthy behaviors change such as weight loss and increasing physical activity $[15,29]$. The applicability of MI across a variety of issues, its brief and specific interactions, and practical use in combination with other active treatment methods has intrigued 
many health care practitioners and lead to explorations of the utility of MI in other areas of health care practice [29]. Two recent studies examined the effectiveness of MI in a population of workers with disabling musculoskeletal disorders [16, 17]. MI led to higher percentages of RTW at the end of rehabilitation and more sustainable RTW over a 1-year follow-up. MI is a promising intervention in occupational rehabilitation. Characteristics of MI techniques that complement its suitability for use in occupational rehabilitation programs, focussing on behavioral change include: (1) effectiveness with clients who are ambivalent or reluctant in changing their behavior; (2) efficaciousness even in small treatment quantities; (3) application across age, sex, cultural and socioeconomic status; and (4) fit in combination with conventional interventions and programs $[13,30]$. Each of these will be discussed in more detail below.

\subsection{Difficult, reluctant and ambivalent clients}

MI appears to be particularly helpful with clients who are angry, oppositional, less motivated, or reluctant/not ready for change [13]. Workers who experience complications with the compensation system often feel frustrated, which can interfere with rehabilitation and the RTW process [21]. For these workers, action-oriented approaches aimed at behavior change will likely evoke resistance [13]. This can be further exacerbated if the therapist is perceived as being confrontational [31]. Disputing resistance is seen as counterproductive in MI and evokes defense of counter change arguments, undermining behavior change [29]. One of the principles of MI is to refrain from actively opposing the client's resistance and instead to go along with it using reflective listening skills to engage the individual in the problem-solving process [14].

Expressing empathy in MI involves reflective listening, or accurate empathy as defined by Carl Rogers [32]. Essential to the principle of accurate empathy is a client-centred approach, which provides a supportive atmosphere and where ambivalence or reluctance is viewed as a normal human experience rather than as pathology [32]. The role of the OT in providing a supportive and empathetic environment is consistent with a client-centered approach that honours autonomy and allows the injured worker to choose if, when, and how to change [13]. Autonomy is valued in MI and OT practice. In MI, the role of the practitioner is not to provide all the answers but to instead recognize that the client has important insight and is capable of finding solutions to his or her problems. OTs believe that people have the right and capacity to make decisions about their own life and they have the right to informed choice [33]. Resistance in MI is seen as an interpersonal phenomenon rather than an individual struggle and can be used to create a new approach toward change [14]. When resistance to change is expressed by an injured worker, it can act as a cue for the OT to respond differently [32] because efforts to force resolution in a specific direction, through persuasion or punishment, can be counterproductive and strengthen the behavior intended to be diminished [14].

Evidence from studies on addictive behavior, health behavior, and treatment adherence shows that MI is most beneficial with individuals who are less prepared to change or those in the Pre-contemplation and Contemplation stages [13]. In most occupational rehabilitation settings, the injured worker is expected to function at the Action stage regardless of what stage they are actually in. This mismatch can increase conflict and minimize participation in rehabilitation and the RTW process [13, 22]. From a readiness for change perspective, this occurs due to a misalignment in the stages of change between the therapist and injured worker and can be a source of frustration and resistance [13]. MI is intended to identify and resolve ambivalence in a particular direction of change; however, the focus is on the interests and concerns of the individual with commitment to change facilitated by eliciting the individual's intrinsic motivation for change [12, 14].

Evoking an individual's intrinsic motivation for change is enhanced in both MI and OT by drawing on the client's perceptions, goals and values [14]. Eliciting change talk (identifying an individual's desires, abilities, reasons, and need for change) to bring about constructive behavior change is specific to MI. Adopting strategies to elicit change talk may provide an approach that is more consistent with the values and beliefs of OT practice than current occupational rehabilitation methods used to bring about change. This may have important implications for injured workers who struggle with repeated disability episodes, or who feel as though they were forced back to work before they were ready. Repeated disability episodes may cause an injured worker to further withdraw from the workplace, leading to more barriers to sustainable RTW [34].

In both MI and OT practice, the client is viewed as the expert of the partnership by respecting the 
perspective of the client [35]. An essential goal of MI is to increase importance for change from the client's perspective by creating conflict through the exploration of discrepancy [32]. Conflict is an important concept in several psychological theories and it has the potential to increase ambivalence when an individual struggles between indulging in and resisting the behavior [14]. In MI, ambivalence is addressed with specific questions and reflections used by the practitioner to create a discrepancy between the client's problem behavior and personal values. While creating discrepancy is not a typical clinical practice in OT, fostering awareness of troubling behavior is typical [35]. Often in hopes of bringing about change, OTs will encourage clients to consider the perceived benefits and disadvantages of a particular course of action to help the client realize when occupation and behavior conflict with personal goals [35]. In summary, the theoretical foundations and clinical practice of OT are aligned with MI.

\subsection{Efficacious in small doses}

Workers' compensation issues can negatively impact an injured worker's self-efficacy [4]. MI attempts to enhance the confidence of the individual in the ability to cope with obstacles to successfully change and maintain that change [32]. Readiness for change appears to be related to two factors: the level of importance attributed to the change for the client, and confidence in successfully creating the change [14]. The client's self-efficacy is a pivotal component of motivation and a good indication of treatment outcome [32]. Occupations organize behavior, enable expression and management of self-identify, and increase self-efficacy and social connectedness [33]. These are important in a client's ability to move through the various stages of change and maintain intended behavior [33]. Compensation issues and delays, coupled with prolonged occupational interventions, can negatively affect an injured worker's role identity and self-efficacy, impacting ability to RTW. MI's brief and specific interactions may be of practical use in these situations.

Behavior change that occurs during treatment usually takes place within the first few sessions of MI [14]. However, recent research on MI evaluating a wide range of problem behaviors including substance use, risky behavior and decreased participation in treatment suggests a dose effect where more sessions are likely to generate more behavioral change [24]. In a meta-analysis completed by Rubak et al. [15], MI interventions were used with various target behaviors including alcohol abuse, psychiatric diagnoses, addiction, smoking cessation and physiological problems. One MI session showed an effect in $40 \%$ of the studies; however, with five or more encounters, $87 \%$ of the studies demonstrated an effect [15]. Therefore, while one MI session can produce an effect, the likelihood of an effect increased significantly with a higher number of sessions completed [15]. In addition, strength in commitment language (commitment, activation, taking steps), is associated with behavior change. Therefore, the quality of MI sessions to evoke commitment language is essential to behavior change [36]. Across a range of disease and problem areas, MI generally produces a small to medium effect in improving health-related outcomes with the effects of MI shown to be durable up to at least one-year post treatment [13, 17, 24].

\subsection{Applicable across gender, age and cultural boundaries}

MI is equally effective with male and female clients and across a wide range of ages and has been successfully used with adolescents, adults and the elderly [24]. MI is a cognitively based intervention that requires a level of formal and abstract reasoning; therefore, it is likely not applicable to those that are very young or anyone who has a severe cognitive impairment [24]. While MI could successfully be applied to many injured workers, it may not be appropriate for injured workers who have a severe brain injury or a traumatic psychological injury. Some studies have found MI to be particularly effective with individuals from certain ethnic groups [13, 24]. The non-confrontational, supportive and client-centered approach used in MI may represent a more respectful and relatable rehabilitation approach for some ethnic groups [24].

MI effectively draws from a range of theories and lines of research to describe why and how it works and has been shown to be effective across a spectrum of lifestyle problems and diseases [24]. A key distinction between MI and many other clinical approaches is regardless of what problem areas are addressed, it will not work well if it is considered a technical approach that is applied to clients [37]. Instead, MI should be considered a way of "being" with clients where MI is done for and with them [12]. MI is a useful clinical skill that lends itself well to OT practice because the client-centered collaborative approach honoring the client's autonomy is consistent with 
the beliefs of a client-centred partnership valued in OT practice. Also, the consciously directive method of MI, aimed at resolving ambivalence, allows for interventions directed towards change.

\subsection{Integration with other treatment approaches}

MI has been demonstrated to be an effective clinical tool on its own and in addition to other evidence-based methods when used with clients where ambivalence and motivation are obstacles to change $[24,29]$. When MI is used as a prelude to treatment, its effects have proven to endure across time, suggesting a synergistic effect of MI with other treatments [13]. The clinical style of MI has been used with feedback from structured assessments and is known as Motivational Enhancement Therapy (MET) [28]. While feedback from structured assessments is useful, this is not inherent or an essential component of MI [28]. Although MET has been successfully used with substance abuse populations, it is unknown whether problem feedback from structured assessments is a valuable addition beyond this population [28]. For example, it is unknown if giving a depressed injured worker the results of a mood screening test in addition to active physical treatment would lead to more or less psychosocial barriers affecting rehabilitation outcomes and RTW. Until the benefits of MET can be generalized to the injured worker population, another possibility is using MI with injured workers throughout the treatment process because ambivalence does not vanish when an active treatment such as community physical therapy or a work conditioning program has started [14]. New motivational challenges may develop during the process of rehabilitation, especially as more difficult phases of the treatment process are reached, such as immediately before discharge from community therapy or a work conditioning program [29]. During these times, returning to MI strategies may help resolve any new issues that occur [14].

The outcome of several studies using MI with a range of physiological and psychological conditions concluded clients who receive MI at the commencement of treatment are more likely to remain in treatment longer, adhere to treatment recommendations, and experience significantly better outcomes compared to clients who received the same treatment without MI [13, 14, 24, 31]. Therefore, MI in conjunction with standard occupational rehabilitation services may produce better RTW outcomes with injured workers. In addition, MI has been shown to increase the probability that individuals will return for further treatment [14]. This could increase the opportunity for ambivalent injured workers to receive additional services needed for pursuing sustained behavior change. This is an important consideration for OTs working with injured workers, who are often reluctant to commence or continue to participate in occupational rehabilitation programs.

MI effects were found to be equivalent to other evidence-based treatments, such as cognitive behavioral therapy [13, 24]. The primary advantage of MI over comparable alternative treatments is the shorter duration of care required to achieve successful results [24]. Two recent studies involving MI and RTW demonstrated only one to two MI sessions were required to achieve long term behavior change established through sustainable RTW outcomes [16, 17]. The equivalent success rates but shorter time commitment of MI compared to other evidence-based therapies may make it a more cost effective and practical approach for OTs to address ambivalence with injured workers [24].

\section{Integrating components of MOHO with MI in occupational rehabilitation}

The person characteristics described in MOHO can be related to elements of MI. Characteristics of these models and interventions can impact RTW change processes in occupational rehabilitation. (See Table 1).

\subsection{Personal causation and self-efficacy}

Personal causation and self-efficacy are both concerned with an individual's perception of the ability to complete tasks [9]. These are important to the RTW process because an injured worker's belief in the ability to complete work tasks effectively is a significant predictor or RTW [5]. Higher personal causation is found among those who RTW compared to those who do not [38].

\subsection{Values and eliciting change talk}

Beliefs about occupations an individual considers important are associated with values. A sense of worth and belonging encourages engagement in activities that support an injured worker's values [9]. If career values are compromised through the process of managing a work-related injury, then 
Table 1

Characteristics of the Model of Human Occupation (MOHO) and Motivational Interviewing (MI) Applied to Occupational Rehabilitation

\begin{tabular}{|c|c|c|}
\hline $\mathrm{MOHO}$ & MI & Occupational Rehabilitation \\
\hline \multicolumn{3}{|l|}{ Volition } \\
\hline - Personal Causation & - Self-efficacy & $\begin{array}{l}\text { - Significantly higher personal causation among } \\
\text { those who RTW compared to those that do not } \\
\text { [38] } \\
\text { - Self-efficacy is a significant predictor of RTW [5] }\end{array}$ \\
\hline \multirow[t]{2}{*}{ - Values } & $\begin{array}{l}\text { - Eliciting Change Talk (Desires, Abilities, } \\
\text { Reasons, Needs) }\end{array}$ & $\begin{array}{l}\text { - Career values vital to decision making regarding } \\
\text { RTW [7] }\end{array}$ \\
\hline & & $\begin{array}{l}\text { - Individuals are more willing to accept and act on } \\
\text { self-motivational statements [39] }\end{array}$ \\
\hline - Interests & - Client-centered & $\begin{array}{l}\text { - Volition factors such as interests affects RTW } \\
\text { decisions [40] } \\
\text { - High work autonomy facilitates work functioning } \\
\text { [41] }\end{array}$ \\
\hline \multicolumn{3}{|l|}{ Habituation } \\
\hline • Habits & - Creating discrepancy & $\begin{array}{l}\text { - Habituation is essential in determining future work } \\
\text { potential [42] } \\
\text { - Creating conflict through exploration of } \\
\text { discrepancy increases importance for change [32] }\end{array}$ \\
\hline - Roles & $\begin{array}{l}\text { - Commitment language (Commitment, } \\
\text { Activation, Taking Steps) }\end{array}$ & $\begin{array}{l}\text { - Long term work role disruption is a barrier to } \\
\text { work success [18] } \\
\text { - Commitment directly predicts behavior change } \\
\text { [36] }\end{array}$ \\
\hline \multicolumn{3}{|l|}{ Performance Capacity } \\
\hline $\begin{array}{l}\text { - Cognitive and Physical } \\
\text { Skills }\end{array}$ & - Directive in approach & $\begin{array}{l}\text { - Limited motor, process and } \\
\text { communication/interaction skills are barriers to } \\
\text { work [7] } \\
\text { - MI is an appropriate approach when there is a } \\
\text { clear and desired direction for change [13] }\end{array}$ \\
\hline
\end{tabular}

one can expect a significant impact upon decisionmaking in returning to work [7]. In MI, behavioral change begins with eliciting change talk, which is any expressed language favoring change. Evidence supports the belief that individuals are more willing to accept and act on self-motivational statements [39]. Eliciting an injured worker's desires, abilities, reasons, and needs (DARN) will foster an intrinsic motivation to generate change by focusing on values.

\subsection{Interests and client-centered practice}

Occupational interests can influence the type of work in which a person chooses to engage. Changes to the work environment and/or position due to a work-related injury remove a worker from what is interesting, pleasurable or satisfying, this can affect their decision to RTW [40]. Often workers who find their work satisfying have the ability to choose and engage in work they enjoy, whether it be for the physical aspects of the position, the intellectual stimulation, or social reasons [18]. Client-centered practice is a key element of MOHO and of MI. Both $\mathrm{MOHO}$ and $\mathrm{MI}$ emphasize the client is the focal point and the client is capable of exploring and resolving their own problems. Often in occupational rehabilitation, the client is directed in what they should do to RTW, rather than focusing on what the client believes is important to do to RTW. Essential to client-centered practice in MI is autonomy, and a high level of autonomy facilitates work functioning [41]. A focus on the aspects of RTW that the injured worker selects will encourage interest in work and participation in occupational behavior.

\subsection{Habits and creating discrepancy}

Habits shape occupational behavior by influencing performance in routine activities, regulating how time is used, and creating styles of behavior [18]. Habits involve learned ways of completing activities. Disruption to occupational habits can establish new habits that may be maladaptive and possibly harmful to the injured worker. Habituation after a work-related injury is essential in determining future work potential [42] because appropriate organization of actions into patterns and routines is required to resume effective work habits. Increasing 
importance for change from the client's perspective by creating conflict through the exploration of discrepancy is an essential goal of MI [32] and of significant importance when an injured worker is unable to overcome maladaptive or harmful occupational behavior. Creating discrepancy between an injured worker's occupational behavior and occupational goals is fundamental in driving motivation for change.

\subsection{Roles and commitment language}

Roles shape identity and work can be an important part of an individual's identity [18]. A work-related injury or disability can significantly impact the worker role and long-term work role disruption is a barrier to work success [18]. Changes to the worker role for those who were committed to work before their injury can cause substantial internal struggle and external discord with supervisors or co-workers. The more an individual's identity is defined by the worker role, the more essential it is for that individual to work [18]. However, when the worker role identity changes due to a work injury or illness, ambivalence about returning to work and commitment to the worker role may change. Resolution of ambivalence is essential to the efficacy of MI and commitment language (language describing an individual's pledge to commitment, activation, or taking steps to change) in MI directly predicts behavior change [36]. The public nature of verbal commitments, reward of committing to and achieving obligations, or consequences of not meeting an obligation are reasons an injured worker may carefully choose the strength of their commitment language during MI to match their intentions after the MI session is completed [36]. The incorporation of MI in occupational rehabilitation should focus on the strength of commitment language, which can inform occupational rehabilitation practitioners of the intended level of occupational behavior change. This can provide valuable information regarding the injured worker's level of readiness to change and the level of disruption to the worker role.

\subsection{Performance capacity and directive in approach}

Performance capacity includes the underlying physical and mental abilities of an individual and how these are applied and understood in performance [9]. A work-related injury can cause limitations with motor, process and communication/interaction skills, which are barriers to work [7]. A work-related injury affecting performance capacity may result in anger and resistance of an injured worker who believes steps could have been implemented to prevent the injury, or for the injured worker who experiences complications in the RTW process and believe treatment/intervention could have started sooner. Injured workers who sustain cognitive and/or physical injury that impact performance capacity may struggle with reasonable expectations regarding successful RTW [18]. Some workers may underestimate the impact of injury to their capacities while others may overestimate the severity of the injury [18]. Both possibilities could lead an injured worker to inaccurately formulate reasonable expectations for returning to work and result in participation of occupational behavior preventing a successful RTW. More often, work related injuries that affect a worker's capacities result in uncertainty of what an injured worker can and cannot do resulting in ambivalence regarding RTW and participation in occupational behaviors. While MI postulates that resolving ambivalence and change is the decision of the client, $\mathrm{MI}$ is different from other client-centered therapies because it is directive and goal oriented [39]. MI is an appropriate approach when there is a clear and desired direction for change [13]. The use of MI in occupational rehabilitation may be especially effective for injured workers who are unsure about their capacities and abilities to RTW because occupational rehabilitation is directive with a focus on RTW.

\section{Implications for practice}

\subsection{Summary of $\mathrm{MOHO}$ and MI in occupational rehabilitation}

Like the Readiness for Change Model, the MOHO provides a deeper understanding of an individual's motivation for change and the fluctuations of the readiness stage of the injured worker [25]. The integration of MOHO and MI in occupational rehabilitation may provide OTs with a model and approach to better understand an injured workers' decision-making process. This approach can facilitate participation in occupational behavior at each stage of change [25]. (See Table 2). The integration of MOHO and MI provides OTs working in occupational rehabilitation with important implications for practice including: (1) a bridge to close the gap between the participation and inclusion of 
Table 2

Integrating Stages of Change, Model of Human Occupation (MOHO), and Motivational Interviewing (MI) in Occupational Rehabilitation

\begin{tabular}{|c|c|c|}
\hline 5 stages of RTW & MOHO subsystems & MI Intervention using MOHO framework \\
\hline $\begin{array}{l}\text { 1. Precontemplation: } \\
\text { Injured workers absent } \\
\text { from work are not } \\
\text { considering or initiating } \\
\text { behaviors associated } \\
\text { with RTW }\end{array}$ & $\begin{array}{l}\text { Volition } \\
\text { - Lack of sense of self-efficacy and } \\
\text { perceived incumbency } \\
\text { Values \& Interest } \\
\text { - Importance of work is low } \\
\text { Influencing Environmental Factors } \\
\text { - Discord with employer, lack of } \\
\text { suitable job options }\end{array}$ & $\begin{array}{l}\text { - Collaboration with worker and provide a safe } \\
\text { and supportive environment honoring the } \\
\text { client's expertise and perspective } \\
\text { - Support autonomy- workers' right and } \\
\text { capacity for self-direction } \\
\text { - Determine importance for change and level of } \\
\text { self-efficacy }\end{array}$ \\
\hline $\begin{array}{l}\text { 2. Contemplation: Injured } \\
\text { workers are ambivalent } \\
\text { about RTW }\end{array}$ & $\begin{array}{l}\text { Volition } \\
\text { - RTW is a possibility } \\
\text { Values and Interest } \\
\text { - Conflict with behavior and values } \\
\text { Influencing Environmental Factors } \\
\text { - Discord with employer, lack of } \\
\text { suitable job options }\end{array}$ & $\begin{array}{l}\text { - Increase level of readiness and importance for } \\
\text { change using the evoking process } \\
\text { - Exploration of factors that influence RTW - } \\
\text { DARN- Desire, Reasons, Abilities, Need for } \\
\text { Change } \\
\text { - Focus on values and interests -what is } \\
\text { important and meaningful to the worker to } \\
\text { generate change }\end{array}$ \\
\hline $\begin{array}{l}\text { 3. Preparation: Injured } \\
\text { workers seek } \\
\text { information about } \\
\text { RTW, test their abilities } \\
\text { to RTW, and make } \\
\text { tangible RTW plans }\end{array}$ & $\begin{array}{l}\text { Volition } \\
\text { - Improving personal causation } \\
\text { specifically self-efficacy and } \\
\text { capacity } \\
\text { Habituation } \\
\text { - Establishing worker role identity } \\
\text { and routines for RTW } \\
\text { Influencing Environmental Factors } \\
\text { - Ability to test RTW plans in the } \\
\text { work environment, level of support } \\
\text { from co-workers/supervisors, } \\
\text { access to information }\end{array}$ & $\begin{array}{l}\text { - Increase commitment to change from client's } \\
\text { perspective with the understanding that the } \\
\text { resources for change lie within the worker } \\
\text { - Identification of routines and roles necessary } \\
\text { in the RTW process } \\
\text { - Avoid the righting reflex and providing } \\
\text { suggestions without permission }\end{array}$ \\
\hline $\begin{array}{l}\text { 4. Action: Injured } \\
\text { workers have put their } \\
\text { RTW plan into action } \\
\text { and are working in } \\
\text { some capacity }\end{array}$ & $\begin{array}{l}\text { Volition } \\
\text { - Personal causation is high } \\
\text { Performance Capacity } \\
\text { - Skills in line with present } \\
\text { functioning } \\
\text { Habituation } \\
\text { - Establishing habits and roles } \\
\text { (expectations of the worker) } \\
\text { Influencing Environmental Factors } \\
\text { - Changes to personal and/or work } \\
\text { environment }\end{array}$ & $\begin{array}{l}\text { - Identify a clear and specific change plan that } \\
\text { incorporates new work routine into habit } \\
\text { patterns. } \\
\text { - Identify any barrier hindering successful RTW } \\
\text { to re-establish previous roles lost due to injury } \\
\text { - Identify support and resources and if necessary } \\
\text { identification of new roles }\end{array}$ \\
\hline $\begin{array}{l}\text { 5. Maintenance: Injured } \\
\text { workers use skills and } \\
\text { support systems to } \\
\text { manage situations or } \\
\text { behaviors that can } \\
\text { interfere with RTW }\end{array}$ & $\begin{array}{l}\text { - Internalization of habits and roles } \\
\text { that meet workers expectations } \\
\text { • Establishment of work routines } \\
\text { Influencing Environmental Factors } \\
\text { - Changes to personal and or work } \\
\text { environment }\end{array}$ & $\begin{array}{l}\text { - Integrate work routine into habit patterns. } \\
\text { - Integrate roles into personal sense of meaning }\end{array}$ \\
\hline
\end{tabular}

injured workers in decision-making processes; (2) the linking of a client-centered model with a clientcentered intervention approach; and (3) a theoretical framework and intervention that is theory informed, grounded in evidence, and occupation focused.

In addition, using MI within a MOHO framework can help OTs address two important components of client-centered practice in occupational rehabilitation: (1) clients' desire and ability to participate in RTW decision-making; and (2) the inclusion of the client in the RTW decision-making process. The perceptual gap between these two components has resulted in recommendations for OTs to implement a systematic approach involving clients in RTW decision-making processes of their goals and services. The identification of evidence-based approaches such as MI and work-related assessments based on MOHO concepts could be used to 
better understand injured workers' motivation. This is essential for meeting the client at their level of readiness, and making a meaningful impact on work disability rates.

\section{Conclusion}

MOHO provides a comprehensive framework of impairment and can help OTs better understand RTW change processes, while MI is a useful approach that complements the MOHO model by using a client-centered approach that can support occupational behaviour change. Together they have the potential to reduce work disability and improve RTW outcomes by providing OTs with an understanding of how human occupation is motivated, patterned, and performed, helping OTs meet injured workers at their level of readiness. An understanding of injured workers' volition is necessary in order for occupational behavior change to occur using MI. An injured worker's perception of how performance capacity has been affected by the work injury will also help guide practice. This, in turn, will assist with the reconstruction of the worker role and habits and then ensure commitment to occupational behavior change.

\section{Conflict of interest}

None to report.

\section{References}

[1] Midtsundstad TI, Nielsen RA. Do workplace interventions reduce disability rates? Occupational Medicine. 2016;66:691-7.

[2] Pransky G, Gatchel R, Linton SJ, Loisel P. Improving Return to Work Research. Journal of Occupational Rehabilitation. 2005;15(4):453-7.

[3] Young AE, Roessler RT, Wasiak R, McPherson KM, van Poppel MNM, Anema JR. A Developmental Conceptualization of Return to Work. Journal of Occupational Rehabilitation. 2005;15(4):557-68.

[4] Franche R, Krause N. Readiness for Return to Work Following Injury or Illness: Conceptualizing the Interpersonal Impact of Health Care, Workplace, and Insurance Factors. Journal of Occupational Rehabilitation. 2002; 12(4):233-56.

[5] Krause N, Frank JW, Dasinger LK, Sullivan TJ, Sinclair SJ. Determinants of Duration. of Disability and Return-toWork After Work-Related Injury and Illness Challenges for Future Research. American Journal of Industrial Medicine. 2001;40(4):464-84.
[6] Lam CS, Wiley AH, Siu A, Emmett J. Assessing readiness to work from a stages of change perspective: Implications for return to work. Work. 2010;37:321-9.

[7] Lee J, Kielhofner G. Vocational intervention based on the Model of Human Occupation: A review of evidence. Scandinavian Journal of Occupational Therapy. 2010;17(3):177-90.

[8] Maitra KK, Erway F. Perception of Client-Centered Practice in Occupational Therapists and Their Clients. American Journal of Occupational Therapy. 2006;60(3):298-310.

[9] Kielhofner G. Conceptual Foundations of Occupational Therapy Practice. 4th ed. USA: F.A. Davis Company; 2009.

[10] Kielhofner G. Model of Human Occupation: Theory and Application. 3rd ed. USA: Lippincott Williams \& Wilkins; 2002.

[11] Lee SW, Taylor R, Kielhofner G. Choice, Knowledge, and Utilization of a Practice Theory: A National Study of Occupational Therapists Who Use the Model of Human Occupation. Occupational Therapy in Health Care. 2009;23(1):60-71.

[12] Miller WR, Rollnick S. Motivational Interviewing Helping People Change. 3rd ed. New York, NY: The Guilford Press; 2013.

[13] Hettema J, Steele J, Miller WR. Motivational Interviewing. Annual Review Clinical Psychology. 2005;1:91-111.

[14] Miller WR, Rollnick S. Motivational Interviewing Preparing People for Change. 2nd. ed. New York, NY: The Guilford Press; 2002.

[15] Rubak S, Sandbaek A, Lauritzen T, Christensen B. Motivational interviewing: A systematic review and meta-analysis. British Journal of General Practice. 2005;55(513):305-12.

[16] Park J, Esmail S, Rayani F, Norris CM, Gross DP. Motivational Interviewing for Workers with Disabling Musculoskeletal Disorders: Results of a Cluster Randomized Control Trial. Journal of Occupational Rehabilitation 2017. Advanced online publication DOI 10.1007/s10926-0179712-3

[17] Gross DP, Park J, Rayani F, Norris CM, Esmail S. Motivational Interviewing Improves Sustainable Return to Work in Injured Workers After Rehabilitation: A Cluster Randomized Controlled Trial. Archives of Physical Medicine and Rehabilitation 2017. Advanced online publication DOI http://dx.doi.org/10.1016/j.apmr.2017.06.003.

[18] Kielhofner G, Braveman B, Baron K, Fisher G, Hammel J, Littleton M. The model of human occupation: Understanding the worker who is injured or disabled. Work. 1999;12(1):37-45.

[19] Yngve M, Ekbladh E. Clinical Utility of the worker role interview: A survey study among Swedish users. Scandinavian Journal of Occupational Therapy. 2015;22:416-23.

[20] Kramer P, Hinojosa J, Brasic Royeen C. Perspectives in Human Occupation. Participation in Life. Philadelphia: Lippincott Williams \& Wilkins; 2003.

[21] Dyck DEG. Disability Management: Theory, Strategy \& Industry Practice. 4th ed. Canada: Lexis Nexis; 2009.

[22] Krause N, Rudolph L, Dasinge LK, Deegan LJ, Brand RJ. Psychosocial Job Factors. and Return-to-Work After Compensated Low Back Injury: A Disability Phase Specific Analysis. American Journal of Industrial Medicine. 2001;40(4):37-392.

[23] Waddell, G. Preventing incapacity in people with musculoskeletal disorders. British Medical Bulletin. 2006;7778(1):55-69.

[24] Lundahl B, Burke BL. The Effectiveness and Applicability of Motivational. Interviewing: A Practice-Friendly Review 
of Four Meta-Analyses. Journal of Clinical Psychology. 2009;65(11):1232-45.

[25] Franche R, Corbiere M, Lee H, Breslin C, Hepburn G. The Readiness for Return-To-Work (RRTW) scale: Development and Validation of a Self-report Staging Scale in Lost-time Claimants with Musculoskeletal Disorders. Journal of Occupational Rehabilitation. 2007;17(3):450-72.

[26] Prochaska JO, Velicer WF, Rossi JS, Goldstein MG, Marcus BH, Rakowski W, Fiore C, Harlow LL, Redding CA, Rosenbloom D, Rossi SR. Stages of change and decisional balance for 12 problem behaviors. Health Psychology. 1994;13(1):39-46.

[27] Britt E, Hudson SM, Blampied NM. Motivational Interviewing in Health Settings: A Review. Patient Education and Counseling. 2004;53(2):147-55.

[28] Miller WR, Rollnick S.Ten Things that Motivational Interviewing Is Not. Behavioral and Cognitive Psychotherapy. 2009;37(2):129-40.

[29] Miller RM, Rose GS. Toward a Theory of Motivational Interviewing. American Psychologist. 2009;64(6):527-37.

[30] Butterworth S, Linden A, McClay W, Leo MC. Effect of Motivational Interviewing-Based Health Coaching on Employees' Physical and Mental Health Status. Journal of Occupational Health Psychology. 2006;11(4):358-65.

[31] Lincourt P, Kuettel TJ, Bombardier CH. Motivational interviewing in a group setting with mandated clients A pilot study. Addictive Behaviors. 2002;27(3):381-91.

[32] Burke BL, Arkowitz H, Menchola M. The Efficacy of Motivational Interviewing: A Meta-Analysis of Controlled Clinical Trials. Journal of Consulting and Clinical Psychology. 2003;71(5):843-61.

[33] Townsend E, Stanton S, Law M, Polatajko H, Baptiste S, Thompson-Franson T,. Kramer C, Swedlove F, Brintnell S, Campanile L. Enabling Occupation: An Occupational Therapy Perspective. Ottawa: CAOT Publications ACE; 2002.
[34] Pransky G. Measurement of Outcomes in WDP: Conceptual and Methodological. Considerations and Recommendations for Measuring Outcomes. In Loisel P. \& Anema JR Handbook of Work Disability. New York: Springer Science and Business Media. 2013:95-105.

[35] Townsend E, Polatajko HJ. Enabling Occupation II: Advancing An Occupational. Therapy Vision For Health, Well-Being \& Justice Through Occupation. Ottawa: CAOT Publications ACE; 2007.

[36] Amrhein PC, Miller WR, Yahne CE, Palmer M, Fulcher L. Client commitment language during motivational interviewing predicts drug use outcomes. Journal of Consulting and Clinical Psychology. 2003;71(5):862-78.

[37] Emmons KM, Rollnick S.Motivational Interviewing in Health Care Settings. Opportunities and Limitations. American Journal of Preventative Medicine. 2001;20(1):68-74.

[38] Ekbladh E, Haglund L, Thorell L. The Worker role interview: Preliminary. data on the predictive validity of return to work clients after an insurance medicine investigation. Journal of Occupational Rehabilitation. 2004;14(1):23-9.

[39] Resnicow K, Dilorio C, Soet JE, Borrelli B, Hecht J, Ernst D. Motivational. Interviewing in Health Promotion: It Sounds Like Something is Changing. Health Psychology. 2002;21(5):444-51.

[40] Scheelar JF. A return to worker role after injury: Firefighters seriously injured on the job and the decision to return to high-risk work. Work. 2002;19(1):81-4.

[41] Dorland HF, Abma FI, Roelen AM, Smink JG, Ranchor $\mathrm{AV}$, Bultmann U. Factors influencing work functioning after cancer diagnosis: A focus group study with cancer survivors and occupational health professionals. Support Care Cancer. 2016;24(1):261-6.

[42] Mentrup C, Niehaus A, Kielhofner G. Applying the model of human occupation in work-focused rehabilitation: A case illustration. Work. 1999;12(1):79-92. 